\title{
Pregnancy outcome among gestational diabetes mellitus patients
}

\author{
R Vaghela C. ${ }^{1 *}$, Nanjibhai Sarvaiya V. ${ }^{2}$ \\ DOI: https://doi.org/10.17511/joog.2020.i06.05 \\ 1* Chetna R Vaghela, Assistant Professor, Department of Obstetrics and Gynecology, Government Medical College, Bhavnagar, Gujarat, \\ India. \\ 2 Vipul Nanjibhai Sarvaiya, Assistant Professor, Department of Obstetrics and Gynecology, Government Medical College, Bhavnagar, \\ Gujarat, India.
}

\begin{abstract}
Background and Aim: Though not all babies have birth defects there is still a high probability of congenital defects if the glucose level is not under control during pregnancy and also increased morbidity in terms of hypoglycemia, hyperbilirubinemia, and respiratory distress syndrome warranting NICU admissions. The objective of this study was to find out the maternal and perinatal outcome in patients with gestational diabetes mellitus. Material and Methods: An observational study was conducted among 400 pregnant women who came for antenatal checkups attending the OPD of the department of obstetrics and gynecology, the tertiary care institute of Gujarat, from June 2012 to November 2013. A detailed history including maternal age, parity, BMI, and clinical examination along with antenatal checkup was done. Results: Out of 400 antenatal women tested for OGTT using 75 grams of glucose, about $12.75 \%$ (51) of antenatal women developed GDM. Out of 51 GDM mothers, about $10 \%$ ie., 5 antenatal women had pregnancy-induced hypertension and only 2 developed polyhydramnios and preterm delivery in $11.76 \%$ of antenatal women with GDM Out of 51 babies, $19.6 \%$ of them had respiratory distress syndrome, $7.8 \%$ of the babies requiring NICU admissions because of hypoglycemia, hyperbilirubinemia, and hypocalcemia. Conclusion: Gestational diabetes mellitus was once thought to be a mild condition but now it carries significant short-term and long-term implications for the women and their offspring. Screening for diabetes is mandatory in preventing complications as strict glycemic control is necessary for preventing macrosomia and unexplained stillbirths.
\end{abstract}

Keywords: Gestational diabetes mellitus, Hyperbilirubinemia, Polyhydramnios, Pregnancy

Corresponding Author

Chetna R Vaghela, Assistant Professor, Department of Obstetrics and Gynecology, Government Medical College, Bhavnagar, Gujarat, India. Email: chetnabv@gmail.com

\section{How to Cite this Article}

Vaghela CR, Sarvaiya VN. Pregnancy outcome among gestational diabetes mellitus patients. Obs Gyne Review J Obstet Gynecol. 2020;6(6):131-136. Available From

https://obstetrics.medresearch.in/index.php/joog/art icle/view/126
To Browse

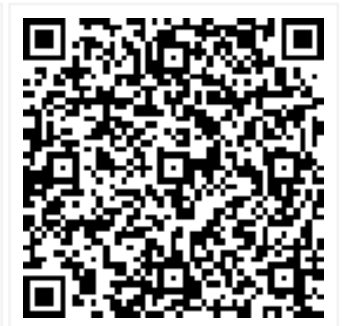

Manuscript Received 2020-12-27

Conflict of Interest No
Review Round 1 2020-12-07

Funding Nil

Review Round 2
$2020-12-17$
$\begin{gathered}\text { Ethical Approval } \\ \text { yes }\end{gathered}$

Review Round 2 yes
Review Round 3

Plagiarism X-checker $8 \%$
Accepted 2020-12-29

(c) 2020 by Chetna R Vaghela, Vipul Nanjibhai Sarvaiya and Published by Siddharth Health Research and Social Welfare Society. This is an Open Áccess article licensed under a Creative Commons Attribution 4.0 International License https://creativecommons.org/licenses/by/4.0/ unported [CC BY 4.0]. 


\section{Introduction}

Gestational diabetes mellitus (GDM) is defined as glucose intolerance detected during pregnancy [1]. The prevalence of GDM is increasing and affects between 1 and 14\% of all pregnancies, caused by a global increase in the number of women with obesity around reproductive age and by more stringent diagnostic criteria for GDM [1-4].

Untreated GDM is associated with an increased rate of neonatal and obstetric complications [5-7] Adverse pregnancy outcomes have been shown to improve with timely diagnosis and treatment of GDM [8]. Gestational diabetes mellitus has been associated with an increased risk for pregnancyinduced hypertension ( $\mathrm{PIH}$ ) with relative risk ranges from 1.4 to 4.15 [8-12]. although some studies suggest that the relation between PIH and GDM is not well understood [13-14].

It also increases the rate of cesarean delivery by up to $57.4 \%$ and has a greater impact in cases of obesity and/or previous history of cesarean section [15-19]. The risk of induction of labor ranges from 33-38\%20-22, premature rupture of membranes (PROM), antepartum hemorrhage $(\mathrm{APH})$, and postpartum hemorrhage (PPH) were associated with GDM [23-25].

Many studies report maternal and fetal complications with GDM but were flawed due to several confounding factors such as obesity, older maternal age, and various other co-morbidities [26].

Most convincing evidence of adverse pregnancy outcome in gestational diabetes was provided by Hyperglycaemia and adverse pregnancy outcome (HAPO) study done in nine countries [27]. GDM is important as it poses a risk to the pregnant woman, her fetus, and newborn baby. Maternal complications include pre-eclampsia, polyhydramnios, elevated rates of operative delivery, PROM, and a higher incidence of Type 2 DM later in life [28].

Fetal complications include spontaneous abortion, malformations, altered fetal growth, unexplained fetal demise, hydramnios whereas neonatal complications include respiratory distress syndrome, hypoglycemia, hypocalcemia, hyperbilirubinemia, long term impaired cognitive development, and risk of inheritance of DM in the future $[29,30]$.
Though not all babies have birth defects there is still a high probability of congenital defects if the glucose level is not under control during pregnancy and also increased morbidity in terms of hypoglycemia, hyperbilirubinemia, and respiratory distress syndrome warranting NICU admissions.

The objective of this study was to find out the maternal and perinatal outcome in patients with gestational diabetes mellitus.

\section{Methods}

An observational study was conducted among 400 pregnant women who came for antenatal checkups attending the OPD of the department of obstetrics and gynecology, tertiary care institute of Gujarat, from June 2012 to November 2013. All pregnant women with a singleton pregnancy were included in the study. A detailed history including maternal age, parity, BMI, and clinical examination along with antenatal checkup was done. Oral glucose tolerance test with 75 grams of glucose was given at 24 to 28 weeks of gestation. Patient was labeled as GDM when anyone value more than the following criteria (FBS > $92 \mathrm{mg} / \mathrm{dl}$, one-hour glucose > $180 \mathrm{mg} / \mathrm{dl}$, 2hour glucose $>153 \mathrm{mg} / \mathrm{dl}$ ). Initially, patients were started with a diabetic diet, if blood sugar was not controlled on diet insulin was started. Any antenatal complications including urinary tract infection, preeclampsia, polyhydramnios, and candidiasis were noted. Both maternal and perinatal outcome in GDM was noted.

\section{Statistical analysis}

The recorded data was compiled and entered in a spreadsheet computer program (Microsoft Excel 2007) and then exported to the data editor page of SPSS version 15 (SPSS Inc., Chicago, Illinois, USA). For all tests, confidence level and level of significance were set at $95 \%$ and $5 \%$ respectively.

\section{Results}

A prospective observational study was conducted among 400 antenatal mothers attending the OPD of the department of obstetrics and gynecology for one year. Among the 400 antenatal mothers' majority of them belong to upper lower socioeconomic status $(65.5 \%)$. The mean age of the study participants was 27.12 years with a standard deviation of 3.12 .

Out of 400 antenatal women tested for OGTT using 75 grams of glucose, about $12.75 \%$ (51) of antenatal women developed GDM. 
Out of 51 GDM mothers, about 10\% ie.,5 antenatal women had pregnancy-induced hypertension and only 2 developed polyhydramnios and preterm delivery in $11.76 \%$ of antenatal women with GDM (Table 1). Out of 51 GDM patients, about 49\% (25) delivered vaginally which included instrumental deliveries too and the remaining 26 were delivered by lower segment cesarean section (Table 2 ).

Out of 51 babies, $19.6 \%$ of them had respiratory distress syndrome, $7.8 \%$ of the babies requiring NICU admissions because of hypoglycemia, hyperbilirubinemia, and hypocalcemia (Table 3 ).

Table-1: Maternal complications in GDM.

\begin{tabular}{|l|l|l|}
\hline \multicolumn{1}{|c|}{ Maternal complications } & Number & \multicolumn{1}{c|}{ Percentage (\%) } \\
\hline PIH & 5 & 9.8 \\
\hline Polyhydramnios & 2 & 3.9 \\
\hline Preterm delivery & 6 & 11.76 \\
\hline
\end{tabular}

Table-2: Mode of delivery.

\begin{tabular}{|l|l|l|}
\hline \multicolumn{1}{|c|}{ Mode of delivery } & \multicolumn{1}{c|}{ Number } & \multicolumn{1}{c|}{ Percentage } \\
\hline Vaginal & 25 & 49.01 \\
\hline LSCS & 26 & 50.9 \\
\hline
\end{tabular}

Table-3: Neonatal complications.

\begin{tabular}{|l|l|l|}
\hline \multicolumn{1}{|c|}{ Neonatal complications } & Number & \multicolumn{1}{c|}{ Percentage (\%) } \\
\hline RDS & 10 & 19.6 \\
\hline Macrosomia & 7 & 13.75 \\
\hline NICU admissions & 4 & 7.8 \\
\hline
\end{tabular}

\section{Discussion}

Different studies have shown the prevalence of GDM varying from 3.8 to $21 \%$ in India. In surveys performed in various cities, the prevalence of GDM was $16.2 \%$ in Chennai, $15 \%$ in Thiruvananthpuram $21 \%$ in Alwaye, $18.8 \%$ in Erode, and $17.5 \%$ in Ludhiana $[30,31]$. The study done by Shridevi AS in Davangere, Karnataka reported a prevalence of $11.7 \% .32$ Some other scholars like Wahi et al. and Kalyani et al. documented a lower prevalence of $6.94 \%$ and $8.33 \%$ respectively $[33,34]$. Several maternal characteristics were associated with an increased risk of developing GDM namely maternal age, pre-pregnancy weight. Similarly, family history of type 2 diabetes was significantly higher in gestational diabetes patients which are following studies from Reece et al35 Maternal complications like polyhydramnios were found in $3.9 \%$ of gestational diabetes patients, pregnancy-induced hypertension in $9.8 \%$ of antenatal women, which is similar to the study done by al - Hakeem et al where polyhydramnios was found in $2.2 \%$ women and preeclampsia in 5.3\% [36].
Women with GDM were three times at high risk for PIH compared to their counterparts. The finding was consistent with several other studies [4-8,37,38] which reported that GDM increased the incidence of PIH. Similarly, another study done in Eastern Ethiopia revealed that mothers who had GDM were three times more likely to develop preeclampsia than women who had not. The association might be due to the nature of co-existing mutual risk factors, such as obesity, advanced maternal age, and family history of diabetes and hypertension [38]. In the present study, there is no significant difference in the mode of delivery which is similar to the study done by Nair et al. In the present study the leading cause for NICU admissions was hyperbilirubinemia followed by respiratory distress which is similar to the study done by Langer et al which shows the leading cause of NICU admissions being hyperbilirubinemia which is about $42 \%$ followed by respiratory complications in babies of GDM mothers which is about $32.3 \%$ [39-41].

\section{Conclusion}

Gestational diabetes mellitus was once thought to be a mild condition but now the current study knows that it carries significant short-term and long-term implications for the women and their offspring.

\section{What does the study add to the existing knowledge?}

Screening for diabetes is mandatory in preventing complications as strict glycemic control is necessary for preventing macrosomia and unexplained stillbirths.

\section{Author's contribution}

Dr. Chetna R Vaghela: Concept, study design Dr. Vipul Nanjibhai Sarvaiya: Manuscript preparation

\section{Reference}

01. American Diabetes Association. Diagnosis and classification of diabetes mellitus. Diabetes Care. 2014;37(suppl 1)s81-S90. doi: $10.2337 /$ dc14-S081 [Crossref]

02. Hunt KJ, Schuller KL. The increasing prevalence of diabetes in pregnancy. Obstet Gynecol Clin N Am. 2007;34(2)173-199.

doi: $10.1016 /$ j.ogc.2007.03.002 [Crossref] 
03. Ferrara A. Increasing prevalence of gestational diabetes mellitus- a public health perspective. Diabetes Care. 2007;30(suppl 2)s141-S146. doi: $10.2337 /$ dc07-s206 [Crossref]

04. Moses RG, Morris GJ, Petocz P, San Gil F, Garg D. The impact of potential new diagnostic crite ria on the prevalence of gestational diabetes me Ilitus in Australia. Med J Aust. 2011;194(7)33840. doi: 10.5694/j.1326-5377.2011.tb03001.x [Crossref]

05. Yang $X$, Hsu-Hage B, Zhang $H$, Zhang $C$, Zhang $Y$, Zhang C. Women with impaired glucose tolerance during pregnancy have significantly poor pregnancy outcomes. Diabetes Care. 2002;25(9)1619-1624.

doi: $10.2337 /$ diacare.25.9.1619 [Crossref]

06. Langer O, Yogev Y, Most O, Xenakis EMJ. Gestational diabetes- the consequences of not treating. Obstet Gynecol. 2005;192(4)989-997. doi: 10.1016/j.ajog.2004.11.039 [Crossref]

07. Sermer $M$, Naylor $C D$, Gare $D J$, Kenshole $A B$, Ritchie J, Farine D, et al. Impact of increasing carbohydrate intolerance on maternal-fetal outcomes in 3637 women without gestational diabetes- the Toronto tri-hospital gestational diabetes project. Obstet Gynecol. 1995;173(1)146-156.

doi: $10.1016 / 0002-9378(95) 90183-3 \quad$ [Crossref]

08. Brown J, Alwan NA, West J, Brown S, Mckinlay C J, Farrar D, Crowther CA. Lifestyle interventions for the treatment of women with gestational dia betes. Coch Database Syst Rev. 2017;5;01197. doi: 10.1002/14651858.CD011970 [Crossref]

09. Casey BM, Lucas MJ, McIntire DD, Leveno KJ. Pregnancy outcomes in women with gestational diabetes compared with the general obstetric population. Obstet Gynecol. 1997;90(6)869-73. doi: $10.1016 / s 0029-7844(97) 00542-5$ [Crossref]

10. Joffe GM, Esterlitz JR, Levine RJ, Clemens JD, Ewell MG, Sibai BM, et al. The relationship between abnormal glucose tolerance and hypertensive disorders of pregnancy in healthy nulliparous women. Am J Obstet Gynecol. 1998;179(4)1032-1037.

doi: $10.1016 / s 0002-9378(98) 70210-8$ [Crossref]
11. Yogev Y, Xenakis EM, Langer O. The association between preeclampsia and the severity of gest ational diabetes- the impact of glycemic control. Am J Obstet Gynecol. 2004;191(5)1655-60. doi: 10.1016/j.ajog.2004.03.074 [Crossref]

12. Suhonen L, Teramo K. Hypertension and preeclampsia in women with gestational glucose intolerance. Acta Obstet Gynecol Scand. $1993 ; 72(4) 269-272$.

doi: $10.3109 / 00016349309068036 \quad$ [Crossref]

13. Jensen DM, Sørensen B, Feilberg-Jørgensen N, Westergaard J, Beck-Nielsen $\mathrm{H}$. Maternal and perinatal outcomes in 143 Danish women with gestational diabetes mellitus and 143 controls with a similar risk profile. Diabetic Med. $2000 ; 17(4) 281-286$.

doi: $10.1046 /$ j.1464-5491.2000.00268.x [Crossref]

14. Jacobson JD, Cousins L. A population-based study of maternal and perinatal outcome in patients with gestational diabetes. Am J Obstet Gynecol. 1989;161(4)981-986.

doi: 10.1016/0002-9378(89)90767-9 [Crossref]

15. Naylor CD, Sermer M, Chen E, Sykora $K$. Cesarean delivery in relation to birth weight and gestational glucose tolerance- pathophysiology or practice style?. JAMA. 1996;275(15)1165-70. [Crossref]

16. Yogev $Y$, Ben-Haroush A, Chen R, Glickman $H$, Kaplan B, Hod M. Active induction management of labor for diabetic pregnancies at term; mode of delivery and fetal outcome-a single center experience. Eur J Obstet Gynecol Reprod Biol. 2004;114(2)166-170.

doi: 10.1016/j.ejogrb.2003.10.017 [Crossref]

17. Saxena P, Tyagi S, Prakash A, Nigam A, Trivedi SS. Pregnancy outcome of women with gestational diabetes in a tertiary level hospital of north India. Soc Med. 2011;36(2)120. doi: $10.4103 / 0970-0218.84130$ [Crossref]

18. Gascho CLL, Leandro DMK. e Silva TR, Silva JC. Predictors of cesarean delivery in pregnant women with gestational diabetes mellitus. Revista Brasileira de Ginecologia e Obstet/RBGO Gynecol Obstet. 2017;39(02)60-65.

doi: $10.1055 / \mathrm{s}-0037-1598644$ [Crossref] 
19. Abu-Heija AT, Al-Bash M, Mathew M. Gestational and pregestational diabetes mellitus in Omani women- comparison of obstetric and perinatal outcomes. Sultan Qaboos University Med J. $2015 ; 15(4)$ e496.

doi: 10.18295/squmj.2015.15.04.009 [Crossref]

20. McMahon M, Ananth C, Liston R. Gestational dia betes mellitus- Risk factors, obstetric complicati ons and infant outcomes. J Reprod Med. 1998;43(4)372-8.

[Crossref]

21. Gasim T. Gestational diabetes mellitus- maternal and perinatal outcomes in 220 Saudi women. Oman Med J. 2012;27(2)140.

doi: 10.5001/omj.2012.29 [Crossref]

22. Peticca $P$, Keely EJ, Walker MC, Yang Q, Bottomley J. Pregnancy outcomes in diabetes subtypes- how do they compare? A provincebased study of Ontario, 2005-2006. J Obstet Gynaecol Canada. 2009;31(6)487-496.

doi: $10.1016 / s 1701-2163(16) 34210-4$ [Crossref]

23. Tan PC, Ling LP, Omar SZ. The 50-g glucose chal lenge test and pregnancy outcome in a multiet hnic Asian population at high risk for gestational diabetes. Int J Gynecol Obstet. 2009;105(1)505. doi: 10.1016/j.ijgo.2008.11.038 [Crossref]

24. Köck K, Köck F, Klein K, Bancher-Todesca D, Helmer $H$. Diabetes mellitus and the risk of preterm birth with regard to the risk of spontaneous preterm birth. J Maternal-Fetal Neonatal Med. 2010;23(9)1004-1008.

doi: $10.3109 / 14767050903551392 \quad$ [Crossref]

25. Bhat M, Ramesha K, Sarma SP, Menon S, Kumar SG. Outcome of gestational diabetes mellitus from a tertiary referral Center in South India- a case- control study. J Obstet Gynecol India. 2012;62(6)644-9.

doi: $10.1007 / \mathrm{s} 13224-012-0226-9 \quad$ [Crossref]

26. Weinert LS. International Association of Diabet es and Pregnancy Study Groups recommend ations on the diagnosis and classification of hyp erglycemia in pregnancy- Comment to the Inter national Association of Diabetes and Pregnancy Study Groups Consensus Panel. Diabetes Care.

2010;33(3)e97. doi: 10.2337/dc10-0719 [Crossref]
27. Metzger BE, Lowe LP, Dyer AR, Trimble ER. Chaovarindr HAPO Study Cooperative Research Group, Hyperglycemia and Adverse Pregnancy Outcomes. N Engl J Med. 2008;358;1991-2002. doi: 10.1056/NEJMoa0707943 [Crossref]

28. Davey RX, Hamblin PS. Selective versus universal screening for gestational diabetes mellitus- An evaluation of predictive risk factors. Med J Aust. 2001;174(3)118-121.

doi: $\quad$ 10.5694/j.1326-5377.2001.tb143181.x [Crossref]

29. Dashe JS, Nathan L, McIntire DD, et al. Correlation between amniotic fluid glucose concentration and amniotic fluid volume in pregnancy complicated by diabetes. Am J Obstet Gynecol. 2000;182(4)901-904.

doi: $10.1016 / \mathrm{s} 0002-9378(00) 70343-7$ [Crossref]

30. DeBoer T, Wewerka S, Bauer PJ, Georgieff MK, Nelson CA. Explicit memory performance in infants of diabetic mothers at 1 year of age. Dev Med Child Neurol. 2005;47(8)525-531.

doi: $10.1017 / \mathrm{s} 0012162205001039 \quad$ [Crossref]

31. Seshiah V, Balaji V, Balaji MS, Sanjeevi CB, Green A. Gestational diabetes mellitus in India. J Assoc Physicians India. 2004;52;707-711. [Crossref]

32. Savitri D Kabade, Durgaprasad M Kabade, Elizabeth Wilson, Karthik SL, Lavanya K. Study of prevalence and outcome of gestational diabetes mellitus at a tertiary care hospital in North Karnataka. Int J Contemp Med Res. 2017;4(2)325-328.

[Crossref]

33. Shridevi AS, Prabhudev P, Bhovi MR. A clinical study of prevalence of gestational diabetes mellitus and associated risk factors at a tertiary care centre in Karnataka, India. Int J Reprod Contracept Obstet Gynecol. 2015;4(6)18401845.

doi: $10.18203 / 2320-1770 . i j r c o g 201 \quad$ [Crossref]

34. Wahi P, Dogra V, Jandial K, Bhagat R, Gupta R, Gupta $S$, et al. Prevalence of Gestational Diabetes Mellitus (GDM) and its Outcomes in Jammu Region. J Assoc Physicians India. $2011 ; 59 ; 227-230$.

[Crossref] 
35. Reece EA, Leuizamon G, Wiznitzer A. Gestational diabetes- the need for a common ground. The Lancet. 2009;373(9677)17891797.

doi: $\quad 10.1016 /$ S0140-6736(09)60515-8 [Crossref]

36. Al-Hakeem MM. Pregnancy outcome of gestational diabetic mothers- experience in a tertiary care centre. J Fami Comm Med. 2006;13(2)55-59.

[Crossref]

37. Hartling L, Dryden DM, Guthrie A, Muise $M$, Vandermeer B, Aktary WM, Pasichnyk D, Seida JC, Donovan L. Screening and diagnosing gestational diabetes mellitus. Evid Rep Technol Assess (Full Rep). 2012;(210)1-327. [Crossref]

38. Gasim T. Gestational diabetes mellitus- maternal and perinatal outcomes in 220 Saudi women. Oman Med J. 2012;27(2)140-144.

doi: 10.5001/omj.2012.29 [Crossref]
39. Nair VG, Sandhu GS, Biswas M, Bhalla R. Evaluation of the incidence and outcome of gestational diabetes mellitus using the current international consensus guidelines for diagnosing hyperglycemia in pregnancy. Int J Reprod Contracept Obstet Gynecol. 2016;5(10)336;1-6.

doi: $10.18203 / 2320-1770 . i j r c o g 20163159$ [Crossref]

40. Langer O, Rodriguez DA, Xenakis EM, McFarland $M B$, Berkus MD, Arredondo F. Intensified versus conventional management of gestational diabetes. Am J Obstet Gynaecol. $1994 ; 170(4) 1036-1047$.

doi: $10.1016 / S 0002-9378(94) 70097-4$ [Crossref]

41. Jovanovic-peterson L, Peterson CM. New strategies for the treatment of gestational diabetes. Israel J Med Sci. 1991;27(8-9)510515.

[Crossref] 